\title{
Ensino por projeto: uma experiência com estudantes de escolas de várzea no Amazonas
}

\author{
Teaching by project: an experience with students from várzea schools in \\ Amazonas
}

\author{
Carmen Lourdes Freitas dos Santos Jacaúna', Roberto Greco"
}

\begin{abstract}
RESUMO
Oportunizar o desenvolvimento de atividades práticas a fim de trabalhar os conteúdos curriculares é uma demanda que vem sendo adotada por muitas escolas. Nessa perspectiva, este trabalho apresenta a avaliação da eficácia de ações educativas orientadas pela pedagogia de projetos, realizada junto aos estudantes do Ensino Fundamental II, de uma escola municipal de Parintins, AM. As ações fizeram parte de um projeto escolar intitulado "Mãos na terra", cujo objetivo foi a implementação de uma horta escolar e o desenvolvimento de ações educativas de cunho transdisciplinar, que valorizem os saberes tradicionais locais, como instrumento motivador da construção do conhecimento científico. Para avaliar a eficácia dessas ações, realizou-se com os estudantes, uma roda de conversa e aplicou-se um questionário com questões semiabertas afim de identificar os seus posicionamentos. Os resultados apontam a necessidade de maior desenvolvimento dessas práticas na escola, visto que a metodologia de projeto instiga os estudantes a participarem das atividades e, contribuem para maiores reflexões em torno dos conteúdos estudados, oportunizando-os a serem protagonistas na construção de seu próprio conhecimento.
\end{abstract}

Palavras-chave: Ensino por projeto; Horta escolar; Saberes tradicionais.

\section{ABSTRACT}

Opportuning the development of practical activities in order to work the curricular content is a demand that has been adopted by many schools. From this perspective, this paper presents the evaluation of the efficacy of educational actions guided by the pedagogy of projects, performed with the students of elementary school II, of a municipal school of Parintins, AM. The actions were part of a school project titled "Hands On Earth", whose objective was the implementation of a school garden and the development of educational actions of a transdisciplinary nature, which value traditional local knowledge, as an instrument Motivator of the construction of scientific knowledge. To evaluate the efficacy of these actions, the students were submitted to a conversation wheel and a questionnaire was applied with semiopen questions in order to identify their positions. The results indicate the need for further development of these practices in the school, since the project methodology Instigs students to participate in the activities and, contribute to greater reflections about the contents studied, Opportunting them to be protagonists in building their own knowledge.

Keywords: Teaching by Project; School Garden; Traditional knowledge.

I Doutoranda do Programa de Pós-graduação em Ensino e História de Ciências da Terra, pelo Instituto de Geociências da Universidade Estadual de Campinas (UNICAMP) carmen.Ifsj@gmail.com ORCID: https://orcid.org/0000-0002-8648-6763 II Professor da Universidade de Campinas (UNICAMP) robertogreco1@yahoo.it ORCID: https://orcid.org/0000-0001$\underline{8137-4386}$ 


\section{INTRODUÇÃO}

Ainda hoje tem regiões remotas, como é o caso do interior da região amazônica, onde ainda são fortes os saberes tradicionais ancestrais. Esses saberes foram repassados das populações nativas para as atuais gerações, fruto do processo de miscigenação com o colonizador. O processo de miscigenação acontece a séculos mas teve uma intensificação da difusão dos saberes construídos por essa população nas últimas décadas. Dentre os fatores atuais responsáveis pela difusão dos saberes tradicionais está a implementação de energia elétrica a regiões longínquas da Amazônia, por meio do Programa de Eletrificação Rural. Conhecido como Projetos luz para todos, o Programa Nacional de Eletrificação Rural foi instituído pelo Decreto $\mathrm{n}^{\circ}$ 4.873, de 11 de novembro de 2003, e foi destinado a propiciar, até o ano de 2008, o atendimento em energia elétrica à parcela da população do meio rural brasileiro que ainda não tivesse acesso a esse serviço público.

De acordo dom os dados da Amazonas Energia, no Estado do Amazonas, a implantação do programa teve por meta prover acesso à energia elétrica a 144.093 novos domicílios no meio rural, baseado no levantamento do IBGE, através do Censo 2000 dos domicílios sem energia elétrica na zona rural do Estado do Amazonas. Além disso, esse projeto também possibilitou o acesso as tecnologias da informação e comunicação como o rádio, TV e a internet, ampliando a difusão do conhecimento na medida em que a informação possui maior alcance pelas mídias.

$\mathrm{Na}$ região, as escolas estão presentes na maioria das comunidades rurais, porém não faltam desafios para os alunos conseguirem frequentar as aulas, devido as distâncias que incluem trajetos realizados de barco ou a pé, que ficam condicionados a flutuação do nível do rio. Dificuldades sócio econômicas das famílias também podem limitar a efetiva participação dos alunos as atividades escolares.

Por outro lado, as escolas também enfrentam dificuldades ligadas a limitações da estrutura física, ferramentas de ensino, e formação de pessoal. Isso impõe muitas vezes a necessidade de ter turmas multisseriadas que formadas por estudantes de anos escolares diferentes, atendidos por um único professor que ministra aulas de 
todas as disciplinas. A baixa densidade populacional e o reduzido número de crianças para formar as turmas também contribuem. Nas escolas do campo é mais frequente a presença de turmas multisseriadas. Para D" Agostini, Taffarel e Santos Júnior (2012), as turmas multisseriadas são uma realidade da Educação do Campo que não pode ser ignorada por terem a seriação como referência da lógica escolar mais adequada para a aprendizagem nessas escolas.

Outro condicionante para a implementação do ensino nas escolas do campo diz respeito ao processo formativo dos professores. Mesmo que os professores se formem nas universidades da região, estes muitas vezes não estão preparados para trabalhar com classes multisseriadas e com escolas do campo, que seguem uma proposta específica para Educação do Campo.

Quando se trata de Educação do Campo, esta começou a fazer parte das discussões nacionais no final da década de 1998, na realização da I Conferência Nacional por uma Educação Básica do Campo, realizada em Luziânia/GO. Esse evento fortaleceu o conceito de Educação do Campo, defendendo o direito dos povos do campo às políticas públicas de educação, no sentido de garantir a ampliação e o acesso da permanência e do direito a escola pública de qualidade; além de respeitar o conhecimento, a cultura, os saberes e os modos de produção do ambiente, dando ao povo do campo o direito de estudar no ambiente em que vive (CNE/CEB n 1, 2002).

Na direção oposta a realidade de muitas escolas que ainda desenvolvem um ensino disciplinar e compartimentado, há escolas que optam por desenvolver um trabalho com o objetivo de sanar as dificuldades enfrentadas em sala de aula, e com o propósito de criar resistência as condições impostas pelos currículos fragmentados, propondo ações educativas que coloquem o professor como o mediador da aprendizagem e o estudante como o construtor do seu conhecimento.

Nessa perspectiva, a Escola Municipal Pedro Reis Ferreira, localizada na zona rural do município de Parintins/AM, propôs a comunidade escolar a implementação de um projeto de ensino intitulado "Mãos na Terra", afim de amenizar a distância entre as necessidades reais de aprendizagem de seus estudantes quanto aos conteúdos escolares, e ao mesmo tempo, resgatar e valorizar os saberes tradicionais 
locais no que se refere ao cultivo da terra, como instrumento motivador da aprendizagem. Nessa perspectiva, essa escola será objeto do presente trabalho.

A pedagogia de projetos insere-se nesse contexto exigindo dos sujeitos uma nova forma de conceber a educação escolar mais flexível e aberta. Para isso, foi necessário que os professores assumissem uma nova forma de conceber a educação, enfrentando o desafio de confrontar uma cultura escolar fragmentada na qual foram formados, passando a desenvolver novas estratégias de ensino.

Em vista do exposto, este trabalho apresenta os resultados dessa ação educativa. A escola já desenvolve práticas onde as atividades cotidianas locais estão presentes, a exemplo do projeto "Mãos na Terra" que dedicou-se à implementação de uma horta escolar, sob a orientação de moradores locais que ensinam aos estudantes, técnicas tradicionais de cultivo do solo.

A implementação da horta escolar propiciou aos estudantes a compreensão da dinâmica natural do contexto amazônico, a planejar e desenvolver técnicas de cultivo do solo adaptadas para terrenos de várzea, lugar onde a escola está localizada. Esses terrenos são inundados periodicamente pelas águas do rio, fenômeno esse que desenvolveu nas populações ribeirinhas dinâmicas de adaptação e técnicas de cultivo do solo singulares.

Na Amazônia, muitos dos critérios intrínsecos a denominações, classificações e técnicas produtivas de cultivo do solo, tem valor científico porque retratam fenômenos ou ocorrências naturais de forma clara, a partir de um conhecimento que foi construído por muitas gerações e que nem sempre são utilizados no contexto escolar.

Para realizar este trabalho, foi necessária a participação dos professores que acompanharam todas as etapas do projeto, desde o planejamento, ao desenvolvimento e avaliação da eficácia dessas atividades. Esses professores muitas vezes sem experiência com a educação do campo, precisaram adaptar-se a essa nova realidade, o que requer maior aprimoramento de sua formação profissional, tanto nos cursos de licenciatura, quanto em sua formação em serviço. 
Para avaliar a eficácia das atividades desenvolvidas no projeto, realizou-se com os estudantes uma roda de conversa e aplicou-se um questionário onde puderam manifestar seus posicionamentos sobre sua aprendizagem, o resgate dos saberes tradicionais locais, seu interesse pelas atividades propostas, bem como as dificuldades enfrentadas. Este trabalho aponta para maiores reflexões acerca das abordagens metodológicas desenvolvidas na escola, com ênfase na pedagogia de projetos. Nessa abordagem, o estudante é agente ativo em sua aprendizagem, isto porque a escola é uma instituição que se organiza através de saberes historicamente acumulados e construídos, que precisam ser resgatados, recuperados e conservados, e a eles acrescidos os construídos no presente.

\section{PEDAGOGIA DE PROJETOS: A PRODUÇÃO DO CONHECIMENTO MEDIADO}

\section{PELOS SABERES LOCAIS}

Por ser uma proposta de intervenção pedagógica, a atividade proposta busca atender a necessidade de aprendizagem, e surge na tentativa de resolver situações problemáticas do cotidiano escolar. Possibilita que os aprendizes, ao decidirem, opinarem, e debaterem questões sobre sua realidade; construam sua autonomia e seu compromisso com o social, constituindo-se como sujeito cultural.

A discussão sobre pedagogia de projeto proposta por John Dewey no início do século $\mathrm{XX}$, pautada numa concepção de que a educação é um processo de vida e não uma preparação para a vida futura, orienta as escolas a definirem propósitos que contemplem a vida presente. Nesses termos, as ações educativas que envolvem a pedagogia de projetos contribuem para uma ressignificação dos espaços de aprendizagem de tal forma que estes corroborem para a formação de sujeitos ativos, reflexivos, atuantes e participantes (HERNANDEZ, 1998).

Freire (1997), acrescenta a essa proposta um diálogo sobre a realidade social, orientando os trabalhos por projeto a uma reflexão sobre as condições de vida da comunidade a que o grupo faz parte, analisando as relações a um contexto social, 
político e ambiental maior, capaz de elaborar propostas de intervenção que visem a transformação social local.

Em busca do diálogo entre a realidade social e a construção do conhecimento, a escola vive novos tempos e compreende que hoje o compromisso do conhecimento científico não se reduz a formação de especialistas nem a obediência cega aos conceitos.

No que se refere a comunicação do saber científico, tanto a escola, quanto as universidades são lugares privilegiados de acesso ao saber letrado, mas ao longo do tempo negam outros saberes entendidos como inoportunos, estranhos, não merecedores de crédito, desprovidos de verdade (MORIN, 2003). Porém, sabemos que as teorias e conteúdos consagrados pela ciência formal "foram balizados e sistematizados por conhecimentos construídos ao longo dos tempos por populações, muitas vezes anônimas, providas de curiosidade e criatividade na forma de compreender a natureza, a nós mesmos e ao ambiente que o cerca" (CHASSOT, 2010, p. 69).

Quando se trata da relação entre história de vida e construção do conhecimento científico, Morin (2003, p. 78), afirma que o importante é "abrir os horizontes e reestabelecer as articulações entre o que foi separado, para se tentar compreender a multidimensionalidade, para se pensar na singularidade com a localidade e com a temporalidade e nunca esquecer a totalidade". É com base nesse pensamento que urge a aproximação, o diálogo entre o saber científico com o saber da tradição, comprovando que além da ciência "outros saberes explicam os problemas fundamentais do mundo e da condição humana; isso porque a objetividade científica não exclui a mente humana, o sujeito individual, a cultura" (MORIN, 2007 p. 58).

Em um país onde há contradições, mestiçagem e pluralismo visíveis como no Brasil, quando se trata de construção do conhecimento, Morin (2007), indica a necessidade de um projeto educacional compatível com essa complexidade por meio de uma visão transdisciplinar. A visão transdisciplinar proposta por esse autor, vislumbra uma educação substanciada pelo pensar complexo que só será possível se 
for uma visão integral do ser humano. Certamente, a questão exige discussão pois, a educação do futuro exigirá um esforço transdisciplinar que seja capaz de juntar ciência e humanidades e romper com a oposição entre natureza e cultura, ultrapassando os limites do conhecimento científico.

Quando Morin (2007) se refere aos limites do conhecimento científico, destaca que não se trata de desconsiderar ou rejeitar o legado do conhecimento produzido pela ciência moderna. Diz respeito antes de tudo, ao estreitamento e ao debate entre a ciência e os saberes que ela silenciou. É procurar alargar e flexibilizar as fronteiras disciplinares, criadas pela especialização extrema do conhecimento, bem como, pensar na produção do conhecimento mais comprometido com as populações que foram relegadas às ausências, fruto do projeto imperialista das ciências modernas.

Considerando o ensino escolar baseado na compreensão transdisciplinar dos fenômenos, as explicações contextualizadas e a integração com diferentes formas de pensar a natureza em suas múltiplas representações, abre-se a possibilidade de diminuir as distâncias dentre as diversas disciplinas evitando a "fragmentação do saber que leva o homem a não ter domínio sobre o próprio conhecimento" (PONTUSCHKA, PAGANELLI, CACETE, 2009, p. 147).

Ao propor um ensino por meio de projetos balizado pelos conhecimentos tradicionais locais, abre-se a possibilidade tanto aos professores quanto aos alunos de exercitarem uma postura investigativa em busca da reconstrução do conhecimento como maneira própria da educação escolar, e implica em um processo recorrente, que começa naturalmente pelo uso do senso comum, e no diálogo com os saberes escolares transforma-se em outros saberes, mais complexos e mais ricos de significados. Logo, conhecer por meio do conhecido "significa sobretudo aceitar que ninguém é propriamente analfabeto já que todos temos uma identidade cultural e histórica e dominamos alguma linguagem" (DEMO, 2011, p. 25).

Com base no exposto, se de um lado acreditamos que as teorias científicas são o nutriente do conhecimento do mundo por parte da comunidade científica. Por outro lado, entendemos que os saberes populares ou da tradição transferido pela oralidade de geração a geração, são alimento que dão vida à compreensão do 
cotidiano por parte de numerosas populações rurais que não tem acesso a circulação dos saberes científicos.

Por meio das ações desenvolvidas no projeto, ao aproximar as teorias científicas aos conhecimentos populares, foi possível obter resultados muito significativos com o diálogo entre as gerações que chegam a surpreender os jovens, "que veem a riqueza dos saberes detidos pelos mais velhos, além da gratificação de ver a academia valorizar aquilo que eles conhecem, geralmente sem valor como conhecimento para muitos" (CHASSOT, 2010, p. 70).

\section{O ESTUDO DO SOLO PERMEADO PELOS SABERES TRADICIONAIS AMAZÔNICOS}

Elemento de grande importância na vida da maioria dos seres vivos, o solo também chamado de terra, é a base de boa parte das atividades humanas no que se refere ao desenvolvimento da agricultura, pecuária, extrativismo, etc. É dele que retiramos parte dos recursos naturais necessários para a nossa sobrevivência.

Diferente do que pensamos, o solo é altamente degradável e bastante afetado pela ação antrópica. Sua poluição afeta particularmente a camada superficial da crosta terrestre que abriga considerável biodiversidade, importantes à manutenção do equilíbrio biológico do planeta. Por ser um elemento imprescindível para a nossa sobrevivência, cabe-nos o compromisso de usar, gozar e dispor desses recursos naturais que ganham maior responsabilidade frente as mudanças ambientais (PRADO et al, 2010).

Quando se trata do solo da Amazônia, este está intimamente ligado a existência de dois grandes ecossistemas terrestres: o de várzea (terrenos inundados periodicamente pelas águas dos rios) e terra firme (terrenos mais altos livres das enchentes). De acordo com critérios adotados por Iriondo (1982, p. 324), "os terrenos de várzea e terra firme compõem a planície amazônica e compreende a faixa deprimida dentro da qual corre o rio, construída por seus depósitos de canal de inundação". A planície Amazônica caracteriza-se por áreas planas e homogêneas, as vezes completamente monótonas, mas com a existência de formações lacustres com 
formas e tamanhos diversos e canais irregulares muito pequenos, de algumas dezenas de metros de largura e frequentemente colmatados (IRIONDO, 1982).

Sobre a dinâmica de formação dos terrenos de várzea (localização da escola em estudo), "esta unidade foi originada por processo de colmatação que ocorre durante as cheias com predomínio da sedimentação fina em ambientes tranquilos, fora da influência direta do canal" (IRIONDO, 1982, p.327). Essa dinâmica forma e transforma os terrenos de várzea, por meio da subida e descida das águas e deposição de sedimentos ocorridos nas margens dos rios de água branca, também conhecidos como água barrenta.

Nos estudos de Sioli (1985), os rios de água barrenta, tem suas nascentes nas cercanias andinas, a exemplo do rio Solimões e rio Amazonas, banham as áreas da planície e desenvolvem uma atividade extraordinariamente acentuada, que modifica constantemente seu curso por meio da erosão e sedimentação intensiva e simultânea, transformando frequentemente os terrenos por onde passam.

Nesse sentido, quando se trata da várzea amazônica como lócus da aprendizagem, as aulas devem proporcionar aos estudantes a capacidade de problematizar questões inerentes ao seu cotidiano, a exemplo do cultivo do solo, orientado pelos saberes tradicionais locais, construídos pelos ribeirinhos ao longo dos tempos. Sob a percepção de Noda (2007), os ribeirinhos, são os habitantes tradicionais das margens dos rios, chamados de "filósofos da natureza", ou "intelectuais da tradição", e mesmo alijados de espaços institucionalizados da construção do saber, constroem conhecimentos pertinentes sobre o mundo e sobre os fenômenos cotidianos a partir de sua experiência de vida, e que apesar de diferentes do conhecimento científicos, são construídos com o mesmo rigor e sistematização.

\section{METODOLOGIA}

O projeto "Mãos na Terra" teve seu contexto na Escola Municipal Pedro Reis Ferreira, localizada na área de várzea do município de Parintins-AM (Figura 1), com os 
alunos e professores do Ensino Fundamental II e toda comunidade escolar. Realizouse entre os meses de agosto de 2017 a maio de 2018. O período de execução justifica-se por ser uma escola que é inundada periodicamente pelas águas do rio, e obedece um calendário específico.

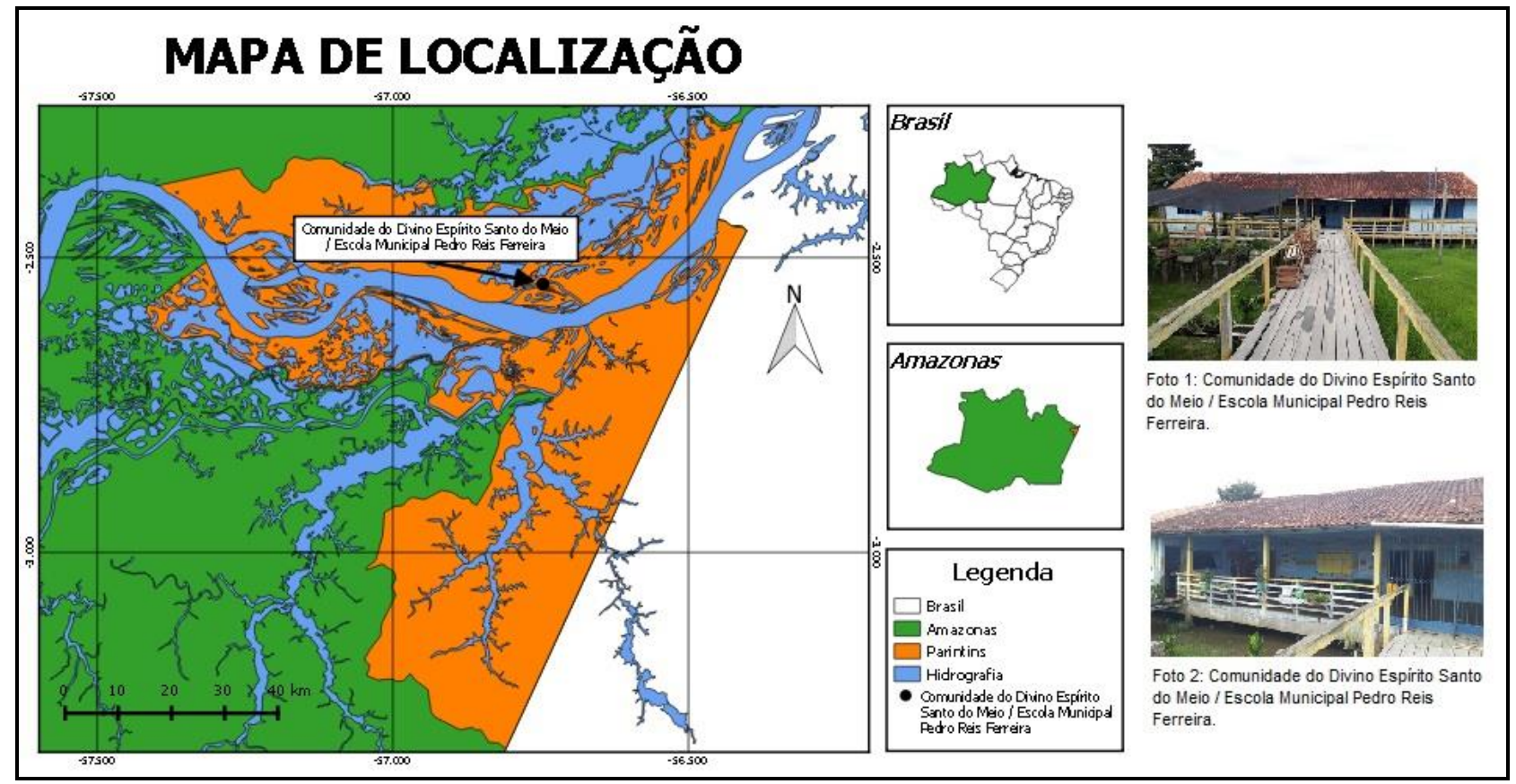

A escola desenvolve seu trabalho baseado nos parâmetros e nas Diretrizes Operacionais da Educação do Campo, a partir da Resolução CNE/CEB n. ${ }^{0}$ 1, de 2000, bem como sob os ditames da Lei de Diretrizes e Bases da Educação Nacional - LDBEN (1996), que prevê atendimento específico à educação das populações que moram no campo. A Educação do Campo vem firmando-se como um projeto transformador da realidade social, com requisitos capazes de fortalecer a formação identitária e a valorização da cultura de seus sujeitos.

Uma especificidade das escolas do campo no Amazonas é, trabalhar com turmas multisseriadas, ou seja, turmas constituídas por alunos de anos escolares diferentes, agrupados em uma mesma sala e com um único professor para ministrar as disciplinas. Tal situação encontra amparo legal na Lei de Diretrizes e Bases da Educação Nacional, Lei $n^{\circ}$ 9.394/96, nos Artigos 23 e 28, os quais dão aos Sistemas de Ensino possibilidade de se 
organizarem com vistas a promover adaptações necessárias às especificidades da vida rural, incluindo adequações curriculares, calendários e metodologias de ensino.

Em verdade, a realidade das salas multisseriadas ainda é um problema vivido por essas escolas pois, muitas vezes, sobrecarrega o professor que precisa trabalhar todas as disciplinas sem que tenha formação para isso, o que, a grosso modo, compromete também a aprendizagem dos estudantes. Infelizmente, o levantamento de propostas de intervenção nessa realidade ainda é pouco discutida nos cursos de formação de professores, principalmente quando se trata de regiões onde essa forma de ensino é frequente como na região Amazônica.

Sob a trilha dos argumentos, o corpo docente da escola adotou em suas práticas, a metodologia de projeto, pensando em proporcionar aos estudantes o conhecimento prático a respeito dos usos, cuidados e cultivo do solo. Seguindo as etapas do projeto, orientaram os estudantes a buscarem informações em livros, revistas, internet. Foi um momento de busca em referenciais teóricos que oferecessem subsídio para a compreensão do que estava sendo estudado.

Além de proporcionar aos estudantes a construção de seu conhecimento e o trabalho em equipe, o projeto teve como objetivo aproveitar espaços das cercanias da escola pouco utilizados, para a criação e manutenção da horta escolar, acreditando que, além de encontrar um ambiente propício na escola, o projeto de criação de uma horta permite a integração entre o saber escolar e os saberes tradicionais locais. Outro ponto fundamental, além da ocupação do espaço físico ocioso, foi a utilização dos alimentos produzidos para complementar a merenda escolar. Fez-se possível, ainda, estimular nos estudantes hábitos alimentares mais saudáveis, e a preservação do meio ambiente.

\subsection{Etapas do Projeto}

$1^{\text {a }}$ Elaboração do projeto: Encontro entre professores, alunos e gestor da escola para o levantamento do problema, pertinência e escolha do tema, planejamento das atividades e critérios adotados na pesquisa. 
$2^{a}$ Escolha do local: Levou-se em consideração a presença de fatores como o espaço que possibilite uma boa execução do projeto, solo propício para plantações, disponibilidade de água, incidência de radiação solar, fácil acesso tanto de professores, quanto para os estudantes.

$3^{a}$ Escolha das espécies cultivadas: Optaram por verduras, legumes e frutas, dentre os quais: couve, cebolinha, coentro, chicória, pimenta de cheiro, tomate, macaxeira, banana. Na hora de escolher o que plantar, foi preciso levar em consideração os produtos favoráveis às características climáticas locais, e ainda, como eles poderiam ser úteis para o consumo.

$4^{\circ}$ Preparação do solo (balcões suspensos): Antes de iniciar a plantação, foi necessário certificar-se de que o solo estava pronto para receber a plantação. Comumente, os solos de várzea não carecem de muito trato. Fez-se necessário retirar o mato, observar a existência de formigas, bem como preparar os balcões. Nessa etapa a participação dos pais foi importante para dar as orientações de acordo com suas técnicas de cultivo.

$5^{a}$ Plantio e o compromisso com os tratos culturais: Cumprindo todas as etapas acima, o próximo passo envolveu o plantio. Algumas espécies foram plantadas com sementes e outras em mudas. Terminada a etapa do plantio, os alunos, junto com os professores e funcionários organizaram-se para porem em prática os cuidados necessários a horta. Chegado o período de colheita, os alimentos foram recolhidos, levados para a cozinha e usados para complementar a merenda escolar; o excedente, distribuído na comunidade.

$6^{\circ}$ Avaliação: Essa etapa foi importante para conhecer os pontos positivos, no que se refere aos ganhos na aprendizagem; bem como os pontos negativos, com o objetivo de serem replanejados e ajustados. Para levantar o posicionamento dos estudantes quanto aos ganhos cognitivos em sua aprendizagem e eficácia das atividades, realizou-se uma roda de conversa e aplicou-se um questionário semiestruturado que serviu para fomentar as análises deste trabalho. 


\subsection{Critérios utilizados para o desenvolvimento da pesquisa}

Para oportunizar os estudantes a conhecerem os passos adotados no desenvolvimento de um trabalho de pesquisa, seguimos as orientações de Pro Bueno (1995), apresentado no Quadro 1.

\section{Quadro 1 - Critérios adotados para a realização do ensino por investigação}

\begin{tabular}{|c|c|c|}
\hline $\begin{array}{c}\text { Passos necessários para uma } \\
\text { investigação }\end{array}$ & Descrição da ação & Ações desenvolvidas \\
\hline $\begin{array}{l}\text { Observação de objetos e } \\
\text { fenômenos }\end{array}$ & $\begin{array}{l}\text { Registro qualitativo dos dados e } \\
\text { descrição das observações }\end{array}$ & Solos de várzea \\
\hline $\begin{array}{l}\text { Medição de objetos e } \\
\text { transformações }\end{array}$ & $\begin{array}{l}\text { Registro quantitativo dos dados, } \\
\text { medições do terreno analisado }\end{array}$ & $\begin{array}{c}\text { Delimitação da área estudada } \\
\text { (perímetro onde a escola está } \\
\text { localizada) }\end{array}$ \\
\hline $\begin{array}{c}\text { Classificação dos objetos e } \\
\text { sistemas }\end{array}$ & $\begin{array}{l}\text { Utilização de critérios para } \\
\text { classificar (categorização) }\end{array}$ & $\begin{array}{c}\text { Terrenos invadidos pelas águas } \\
\text { do rio e terrenos livres das } \\
\text { águas do rio }\end{array}$ \\
\hline $\begin{array}{l}\text { Reconhecimento do } \\
\text { problema }\end{array}$ & $\begin{array}{c}\text { Motivo pelo qual se estuda o } \\
\text { problema apresentado }\end{array}$ & $\begin{array}{l}\text { E um problema presente no } \\
\text { cotidiano dos estudantes }\end{array}$ \\
\hline Formulação das hipóteses & $\begin{array}{c}\text { Estabelecimento de ideias, e } \\
\text { deduções para resolver o } \\
\text { problema }\end{array}$ & $\begin{array}{c}\text { Suposições feitas pelos alunos } \\
\text { acerca da formação dos } \\
\text { terrenos de várzea }\end{array}$ \\
\hline $\begin{array}{l}\text { Identificação das variáveis e } \\
\text { controle de variáveis }\end{array}$ & $\begin{array}{l}\text { Delimitação das variáveis } \\
\text { relevantes e irrelevantes do } \\
\text { problema }\end{array}$ & $\begin{array}{l}\text { Estabelecimento de relações } \\
\text { de dependência sobre a } \\
\text { formação dos solos de várzea } \\
\text { e a subida das águas do rio }\end{array}$ \\
\hline Montagens experimentais & $\begin{array}{c}\text { Seleção de experiências } \\
\text { adequadas }\end{array}$ & $\begin{array}{c}\text { Experimentação em modelos, } \\
\text { manipulação de material } \\
\text { coletado no solo }\end{array}$ \\
\hline Técnica de investigação & $\begin{array}{l}\text { Processos utilizados para coletar } \\
\text { os dados }\end{array}$ & $\begin{array}{c}\text { Observação, anotações sobre } \\
\text { as principais produtos } \\
\text { agrícolas cultivados }\end{array}$ \\
\hline Análise de dados & $\begin{array}{l}\text { Sistematização dos resultados, a } \\
\text { luz da fundamentação teórica }\end{array}$ & $\begin{array}{c}\text { Verificação dos dados, } \\
\text { dialogando com referências } \\
\text { estudadas }\end{array}$ \\
\hline $\begin{array}{l}\text { Estabelecimento de } \\
\text { conclusões }\end{array}$ & $\begin{array}{c}\text { Avaliação crítica dos resultados } \\
\text { (relatório) }\end{array}$ & $\begin{array}{c}\text { Construção e socialização dos } \\
\text { resultados }\end{array}$ \\
\hline
\end{tabular}

Fonte: Adaptado de Pro Bueno, 1995.

As atividades foram iniciadas com a apresentação do tema que seria estudado: Os solos de várzea e a agricultura. Os estudantes foram orientados a fazer observação do solo 
nas cercanias da escola, medir a área estudada e observar as transformações ocorridas no terreno em virtude da subida e descida das águas do rio. Posteriormente, foram orientados a classificar os elementos que constituem esse tipo de solo, a reconhecer os fatores que causam sua transformação, por meio do levantamento de hipóteses e identificação das variáveis. De volta a sala de aula, e de posse das anotações feitas, desenvolveram uma montagem experimental com o objetivo de confirmar que o solo sem a proteção da vegetação, está mais sujeito a erosão. Por fim, analisaram os dados e estabeleceram as conclusões.

Depois de estudar sobre a caracterização do solo de modo geral, seguindo as orientações do quadro acima, os estudantes foram orientados a realizarem reflexões sobre o solo como espaço de cultivo, afim de prover alimentos para complemento da merenda escolar.

Os conhecimentos aprendidos começaram a ser notados por ocasião da implementação da horta escolar, quando professores, alunos e outros colaboradores colocaram a proposta em prática. Em seus escritos, Souza Filho (2016, p. 76) diz que "a horta escolar tem um papel fundamental no ponto de vista educativo, pois funciona como um espaço de descoberta e aprendizagem direta de muitas matérias que são cobradas na sala de aula".

Nessa etapa do trabalho, podemos fazer uso dos conteúdos aprendidos, em particular de conceitos como: planície de inundação, restinga, conservação, manejo, sistema agrícola, ecossistemas, sedimentos, erosão, colmatação, dentre outros. O trabalho com esses conceitos, aliado aos conhecimentos tradicionais foram necessários afim de que essa atividade ganhasse relevância no cotidiano dos estudantes.

Além das atividades aqui apresentadas, os estudantes analisaram a erosão da margem do rio, manusearam o material que compõe o solo e puderam identificar que este é constituído de areia, silte e argila, com características de "baixa resistência ao processo erosivo do rio, bem como a ação antrópica, as contribuições climáticas, a pressão hidráulica causada pelo rio" (CARVALHO, 2012, p. 83). Essas ações estão apresentadas nas figuras 2, 3, 4 e 5 . 
Figura 2 Atividade de observação

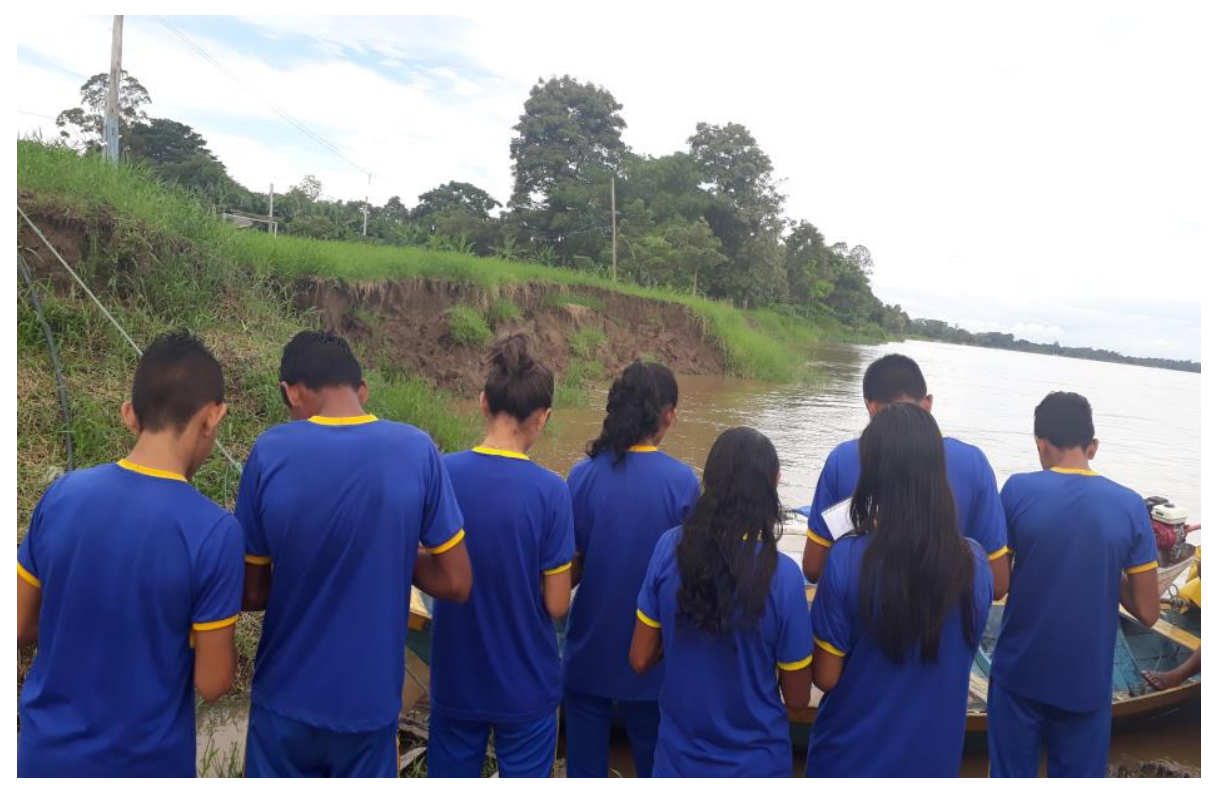

Fonte: Jacaúna, 2019.

Figura 3 Experimentação

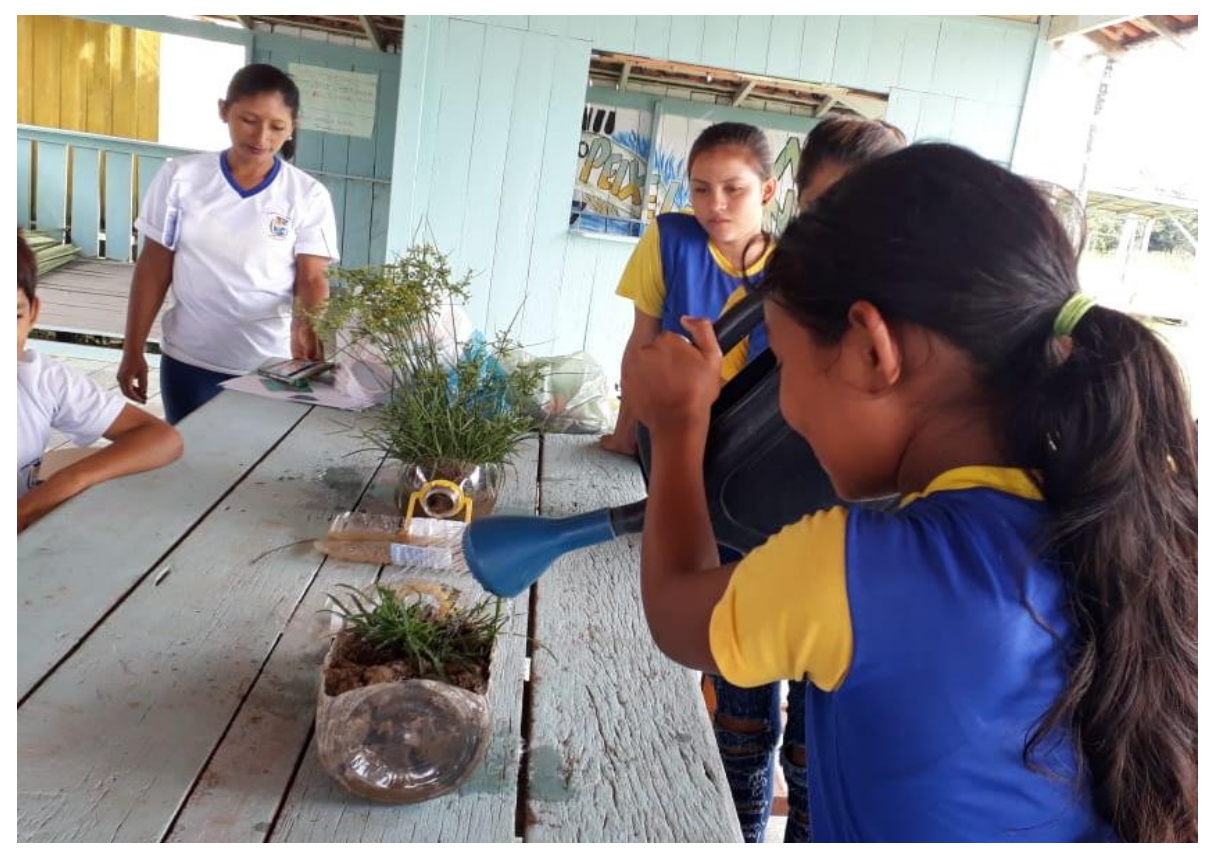

Fonte: Jacaúna, 2019. 
Figura 4: Terreno de várzea

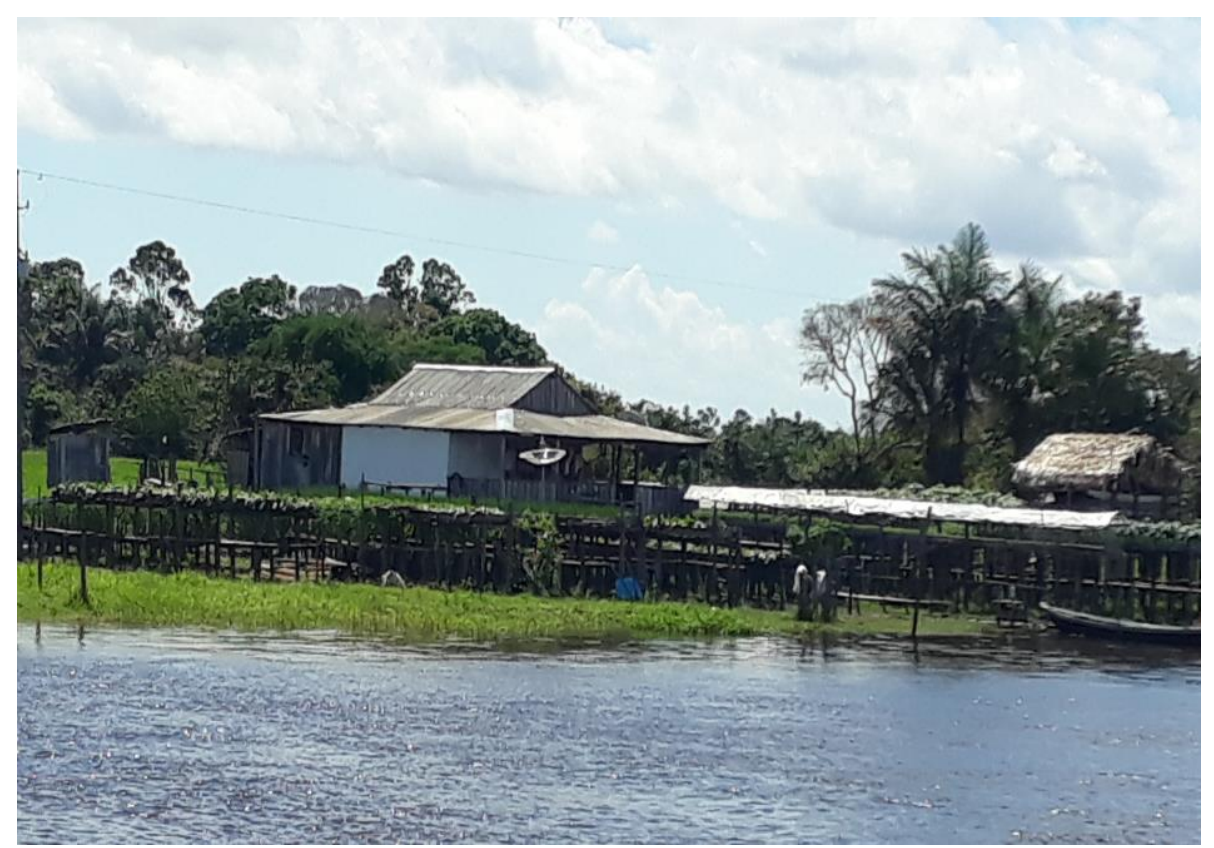

Fonte: Jacaúna, 2019.

Figura 5: Horta escolar

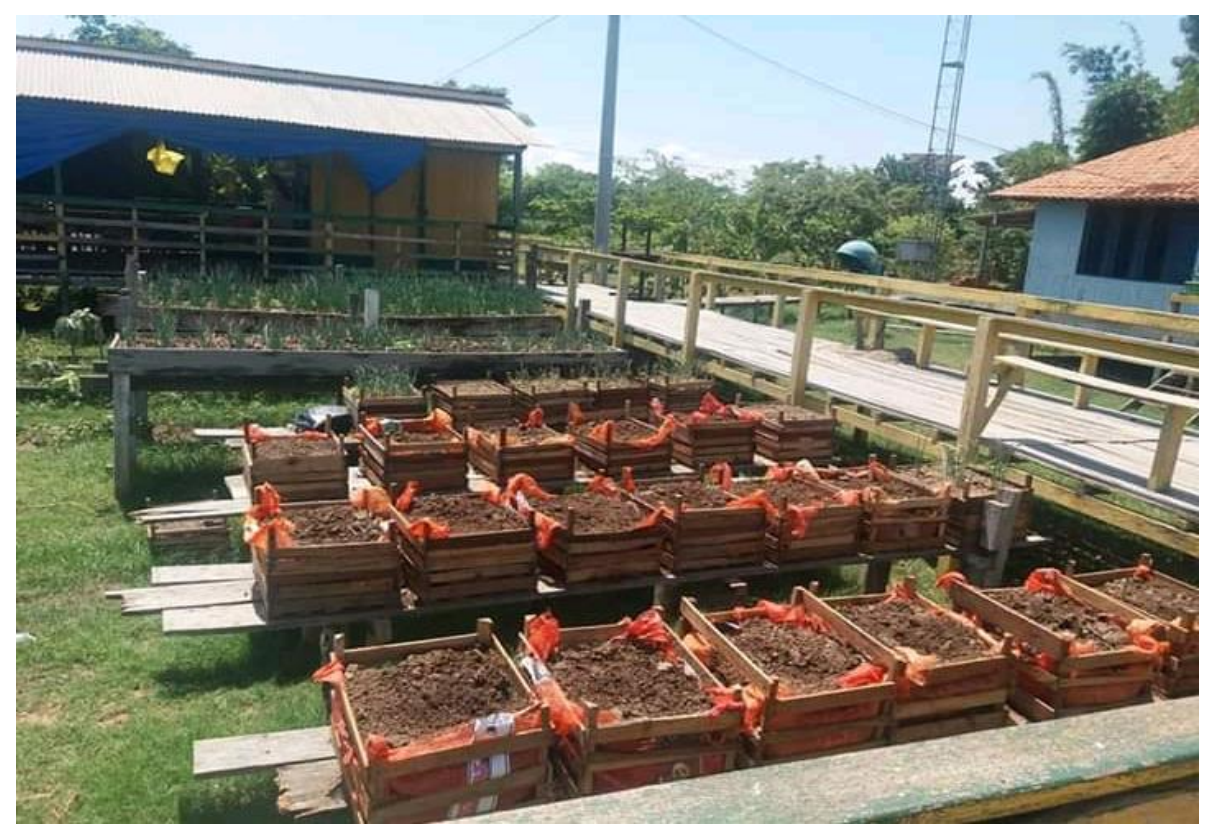

Fonte: Jacaúna, 2019.

\section{RESULTADO}

Para conhecer o posicionamento dos estudantes sobre a eficácia das atividades do projeto "Mãos na Terra", no que diz respeito a sua aprendizagem e o resgate dos saberes 
tradicionais locais, na roda de conversa, instigamos os estudantes a responderem qual a relação da dinâmica das águas com a formação e fertilidade dos terrenos de várzea? Suas respostas foram favoráveis ao desenvolvimento dessas ações e enfatizam que "já tinham conhecimento sobre essa fertilidade".

É de conhecimento local que os solos de várzea são considerados normalmente férteis, em virtude das inundações e deposição sedimentar ocorridas anualmente, causando a renovação de nutrientes do solo. Determinada basicamente pelo regime fluvial, a utilização dessas áreas para a prática da agricultura é muito comum na vida dos ribeirinhos. Para Sternberg (1998),

a água tem influência tanto direta quanto indireta sobre os habitantes da várzea amazônica. O solo criado pela água constitui uma dessas influencias diretas que interferem na própria ocupação e aproveitamento do solo, pois na medida em que se satura, submerge ou deixa enxuto o terreno o que influi não apenas sobre os solos utilizáveis mas sobre a duração do período em que os mesmos (STERNBERG, 1998, p. 15).

Durante anos, esses sujeitos por meio da observação selecionaram culturas e desenvolveram técnicas de cultivo específicas para essas áreas. As culturas selecionadas para o cultivo nesses terrenos, são de ciclo curto e de fácil adaptação.

Quanto a identificação dos fatores responsáveis pela fertilidade dos solos de várzea, os estudantes respondem conforme o que aprenderam com seus familiares sem entrar em um consenso, mas a grosso modo, sabem que "está relacionado ao transporte de nutrientes trazido pelas águas dos rios no período da enchente" (Estudante, 14 anos). O mesmo ocorre sobre como preparar o solo para a plantação. Dizem que "observam se o terreno já está seco, dai, decidem o momento certo de pôr a planta na terra" (Estudante, 14 anos). O início do plantio não tem uma data comum porque nem todos os terrenos ficam livres das águas ao mesmo tempo. A esse respeito, Noda (2007) explicita:

Nas áreas de roças de cultivo de espécies de ciclo curto, os plantios são efetuados de acordo com a descida das águas, iniciando-se com as de ciclo mais longo como a mandioca e a macaxeira, a seguir as espécies de ciclo mais reduzido produtoras de grãos e hortaliças (feijão, milho, melancia, jerimum) [...] nas praias (terras crescidas), são aproveitadas para o plantio de batata-doce e feijões (NODA, 2007, p. 122). 
Todos os produtos plantados nos terrenos de várzea citados por Noda (2007), foram confirmados pelos estudantes que ainda acrescentaram maxixe, melão e cará. $\mathrm{Na}$ sequência, perguntamos aos estudantes o que é feito com os terrenos onde se localizava o roçado (lavoura onde o principal produto cultivado é a mandioca ou macaxeira) que já parou de produzir. Os estudantes respondem que "algumas áreas ficam alagadas", os terrenos mais altos denominados localmente de restinga, "ficam descansando", ou seja, ficam em pousio. Noda (2007), define pousio como uma técnica tradicional de manejo do solo que é utilizada de maneira generalizada pelos agricultores de várzea.

Além das lavouras de curto ciclo, perguntamos que culturas frutíferas podem ser plantadas em terrenos de várzea? Eles citam "mangueira, laranjeira, bananeira, cacau, cupuaçu". Mas, alertam que se a enchente se estender por um período maior, algumas dessas plantações podem morrer.

Como alternativa de cultivo no período da cheia dos rios, os ribeirinhos desenvolveram a técnica dos canteiros ou balcões suspensos. Essa foi a técnica adotada para a implementação da horta no projeto "Mãos na terra", isso porque já estávamos no mês de fevereiro e as águas já se aproximavam do terreno da escola.

Toda a comunidade escolar participou da implementação dos canteiros. Desde a aquisição ou preparação dos caixotes, o preenchimento com o esterco, o plantio das hortaliças, trato cultural à colheita. Geralmente localizado próximo as casas, "os canteiros suspensos são construídos de madeira, preenchido com solo de várzea e esterco de gado disponíveis no local" (NODA, 2007, p. 34).

Ao se referir a construção dos canteiros suspensos, os estudantes sentiram-se motivados em compartilhar suas experiências. Dentre as contribuições disseram que "estes são feitos de madeira tirada da mata ou comprada na cidade" (Estudante de 15 anos). Que estes "precisam ser colocados sobre estacas a uma altura de aproximadamente um metro do solo" (Estudante de 14 anos). Sabem que a madeira precisa ser amarrada com um tipo de cipó retirado da mata, que é mais resistente que a utilização de pregos que oxidam em contato com a água. Dizem que "canoas que já estão furadas e não servem como meio de transporte também podem ser usadas como canteiros suspensos" (Estudante de 17 anos). 
Dessa forma, diante de tantos depoimentos compartilhados na roda de conversa, intuímos que a metodologia de projetos é eficaz e que "a implementação da horta na escola proporciona ganhos positivos na aprendizagem, quando todos sentem-se responsáveis por seus cuidados" (SOUZA FILHO, 2016, p. 42), e quando essa aprendizagem é oriunda dos saberes aprendidos com os pais e/ou familiares, confirma-se a efetivação da aprendizagem a partir dos conhecimentos tradicionais locais.

\section{CONSIDERAÇÕES FINAIS}

A avaliação que fizemos quanto a eficácia do projeto de ensino que oportunizou aos estudantes da Escola Municipal Pedro Reis Ferreira, construírem seus conhecimentos mediados pelos saberes tradicionais locais, leva-nos a compreender que as escolas precisam intensificar essas práticas. A metodologia de projetos ressignifica a pesquisa como princípio educativo, redefine o papel do estudante como sujeito e do professor como mediador na construção dos saberes.

Com o desenvolvimento do projeto "Mãos na Terra" e a implementação da horta escolar, os professores ganharam novas experiências com a educação do campo. Geram maior aprimoramento de sua atuação profissional, além de fortalecer a compreensão sobre seus domínios científicos e técnicos. Outro ponto positivo foi o desenvolvimento da habilidade de articular os conteúdos curriculares com a realidade dos estudantes, no sentido de promover ações que fortaleçam a postura crítica nestes.

Essas ações contribuíram com a aprendizagem dos estudantes resgatando técnicas produtivas populares, com valor científico porque retratam fenômenos ou ocorrências naturais de forma clara, a partir de um conhecimento que foi construído por gerações que não tiveram oportunidade de frequentar o contexto escolar.

Em suma, a partir dos argumentos apresentados, confirmamos que na experiência que tivemos com esses estudantes, promoveu-se a efetivação de um dos principais objetivos do professor em seu trabalho, que é ajudar o estudante no desenvolvimento de suas ideias, seus conceitos, no estabelecimento de relações entre os fatos, comparações, atribuição de significados do que foi estudado e ao mesmo tempo, a aproximação e o 
diálogo entre os saberes tradicionais locais aos saberes escolares, continuamente em transformação.

\section{REFERÊNCIAS}

BRASIL. Lei de Diretrizes e Bases da Educação Nacional No 9.394/96 de 20 de dezembro de 1996.

BRASIL. Resolução $n^{\circ} 1$, de 3 de abril de 2002. Institui Diretrizes Operacionais para a Educação Básica nas Escolas do Campo. In: BRASIL. Ministério da Educação. Secretaria de Educação Continuada, Alfabetização, Diversidade e Inclusão - SECADI. Educação do Campo: marcos normativos/Secretaria de Educação Continuada, Alfabetização, Diversidade e Inclusão. Brasília: SECADI, 2012.

CARVALHO, J. A. L. Erosão nas margens do rio Amazonas: o fenômeno das terras caídas e as implicações na vida dos moradores. 185 p. (Tese de Doutorado. Universidade Federal Fluminense, Programa de Pós-Graduação em Geografia-PPGEO/UFF), Niterói, 2012.

CHASSOT, A. Educação com consciência. 2. Ed. Santa Cruz do Sul: EDUNISC, 2007.

D'AGOSTINI, Adriana; TAFFAREL, Celi Zulke; SANTOS JÚNIOR, Claudio de Lira. Escola Ativa. In: CALDART, Roseli Salete. [et al] (Org). Dicionário da Educação do Campo. Rio de Janeiro, São Paulo: Escola Politécnica de Saúde Joaquim Venâncio, Expressão Popular, 2012.

DEMO, P. Educar pela pesquisa - 9. Ed. Revista - (Coleção educação contemporânea), Campinas, SP: Autores associados, 2011.

FREIRE, P. Pedagogia da autonomia: saberes necessários à prática educativa. São Paulo: Paz e Terra, 1997.

HERNANDEZ, F. Transgressão e mudança na educação: projetos de trabalho. Porta Alegre: ArtMed, 1998.

IRIONDO, M. H. Geomorfologia da planície Amazônica. In: Atlas do Simpósio do Quaternário no Brasil. Anais [...] 1982. p. 323-348.

MORIN, E. Ciência com consciência. 10. ed. Rio de Janeiro: Bertrand Brasil, 2007.

MORIN, E. O problema epistemológico da complexidade. Portugal: Europa-América, 1996.

MORIN, E. A cabeça bem feita. Rio de Janeiro: Bertrand Brasil, 2003. 
NODA, S.N. Agricultura familiar na Amazônia das Águas. Manaus, Editora da Universidade Federal do Amazonas, 2007.

PONTUSCHKA, N. N.; PAGANELLI, T. I.; CACETE, N. H. Para ensinar e aprender geografia. 3. ed. São Paulo: Cortez, 2009.

PRADO, R. B.; TURETTA, A. P.; ANDRADE, A. G. Manejo e Conservação do Solo e da Água no contexto das mudanças ambientais. Embrapa Solos. 2010. 486p.

PRO BUENO, A. Reflexiones para la selección de contenidos procedimentales em ciências. In: Albuquerque - Didácticas de las Ciencias Experimentales, 1995.

SIOLI, H. Amazônia: fundamentos da ecologia da maior região de florestas tropicais. Petrópolis: Vozes, 1985.

SOUZA FILHO, S. M. Pedagogia de hortas: novo foco para essa ferramenta amplamente utilizada pela educação ambiental. 2016. 53 p. Monografia - Curso de Graduação em Licenciatura Plena em Ciências Biológicas, Faculdade das Ciências Agrárias e da Saúde, União Metropolitana de Educação e Cultura. Lauro de Freitas, 2016.

STERNBERG, H. O'R. A água e o homem na Várzea do Careiro. $2^{a}$ Ed. Belém: Museu Paraense Emílio Goeldi, 1998. 330 p. 